\title{
Building Community in Online Doctoral Classrooms: Instructor Practices that Support Community
}

\author{
Sharla Berry \\ University of the Pacific
}

\begin{abstract}
Instructors play a role in helping online students develop a sense of community in virtual classrooms, but little is known about instructors' roles in online graduate programs. To explore the ways in which online instructors helped students create a learning community, defined as a space of connection, closeness and interactivity, the researcher analyzed 50 hours of video footage from four online classrooms as well as the message boards attached to those courses. The researcher triangulated the observations of classroom community with interviews from 13 firstyear students from the online doctoral program to explore their perspectives on instructor strategies that promoted community. Findings from this qualitative case study indicate that instructors helped students develop a sense of community by creating a warm and welcoming tone in the classroom, and by using technology in a variety of ways to engage all students and create a personalized learning experience.
\end{abstract}

Keywords: online learning communities, online graduate education, online doctoral education, online instructor roles

Berry, Sharla (2017). Building community in online doctoral classrooms: instructor practices that support community. Online Learning 21 (2) doi: 10.24059/olj.v21i2.875

\section{Introduction}

Online course enrollments have grown dramatically over the past two decades. One quarter of American college students are in an online degree program, and 32\% have taken at least one online course (Allen \& Seaman, 2013). Although online programs have great potential to expand access to higher education, attrition is a significant challenge to their growth (Patterson \& McFadden, 2009). There are many factors that contribute to online attrition, including high college costs, poor program fit, and lack of technical support or student support services for online students (Angelino, Williams \& Natvig, 2007; Patterson \& McFadden, 2009; Rovai, 2003). Researchers also assert that online students may face challenges in feeling a sense of community, which can contribute to isolation and attrition (Rovai, 2003). 
The term community refers to feelings of membership and belonging within a group (Yuan \& Kim, 2014). In a learning community, students work with peers, instructors, and staff to learn collaboratively and support each other in pursuing academic, social, and emotional goals. A sense of community is associated with increased student engagement, performance, and retention (Ke \& Hoadley, 2009; Stubb, Pyhältö, \& Lonka, 2011).

Instructors play a central role in how online undergraduate students develop a sense of community (Bolliger \& Halupa, 2012; Garrison, Anderson \& Archer, 2010). Despite the importance of instructors to the online experience, few studies have explored instructors' roles in online graduate classes (Ke \& Hoadley, 2009; Rovai, 2003; Yuan \& Kim, 2014). This qualitative case study explores the teaching strategies that instructors in one online doctoral program utilized to help first year students develop a sense of community.

\section{Literature Review}

In an online program, feelings associated with students' sense of community such as belongingness and emotional connection are fostered by frequent positive interactions in the classroom (Garrison, 2011; Rovai, 2007; Yuan \& Kim, 2014). An instructors' style of facilitating an online classroom plays a significant role in the frequency and nature of online students' interactions (Wu \& Hiltz, 2004). Garrison et al. (2010) wrote that online students are more likely to feel a sense of community when instructors facilitate discussions that encourage the participation of all students. Rovai (2007) writes that instructors can use modeling to encourage forms of discussion that are authentic and self-disclosing. When instructors help online students feel comfortable expressing themselves openly in the classroom and encourage students to support the academic and social development of their peers via feedback, constructive criticism and reflective dialogue, students can develop a sense of community in online classrooms (Crawford-Ferre \& Wiest, 2012; Gray, 2004; Rovai, 2007).

Instructors can also use coursework to help facilitate the development of community (Garrison, 2011). For example, researchers found that assignments that require peer knowledge sharing can help students foster a sense of community in online environments (Waycott, Sheard, Thompson \& Clerehan, 2013). Peer knowledge sharing occurs when students publically post their work and must give and receive feedback from peers (Barak \& Rafaeli, 2004; Waycott et al., 2013). This practice, which usually occurs via blogs, wikis or discussion/message boards, requires students to work collaboratively (Barak \& Rafaeli). These assignments also foster critical thinking and create opportunities for students to support their peers' learning (Waycott et al., 2013). By encouraging collaboration, requiring trust and fulfilling students' academic needs, these instructors directed, peer-centered pedagogical practices can help online students develop a sense of community (Alvarez, Espasa \& Guasch, 2012; Wolsey, 2008).

\section{Theoretical Framework}

To understand students' experiences of community in an online doctoral program the researcher used Garrison et al.'s (2010) community of inquiry framework. Garrison and his colleagues suggested that optimal learning occurs in a learning community or community of inquiry, where students and instructors work cohesively and collaboratively in constructing knowledge. In such a learning community, there are robust discussions, open dialogue, and 
students and instructors can give and receive supportive feedback. When a sense of community is cultivated, members of the community experience feelings of connection and belonging (Garrison et al., 2010, Rovai, 2002). Students derive academic, social and emotional benefits from learning in a community of inquiry (Garrison et al., 2010, Rovai, 2002).

In the community of inquiry framework, the educational experience is defined by the presence of three elements-social presence, cognitive presence and teaching presence (Garrison et al., 2010). Social presence is defined as the ability of participants to establish themselves as real in a virtual environment. Social presence emerges when instructors support students in engaging in authentic, self-disclosing dialogue. Cognitive presence is the ability of instructors to facilitate moments of learning that are reflexive and provoke dialogue, and the ability of students to experience a learning environment where they can question, critique and reflect with peers. Teaching presence is the ability of instructors to create a sense of connection with students in the online space through warm, genuine interaction and the development of experiences that students deem worthwhile. The researcher used the community of inquiry framework (Garrison et al., 2010) to explore how instructors' classroom practices helped students in one online doctoral program develop a sense of community.

While research suggests that instructors' classroom practices can be very impactful in helping students develop a sense of community at the undergraduate and graduate levels, little is known about the specific strategies that instructors use inside of classrooms at the doctoral level to help these students develop a sense of community (Ke \& Hoadley, 2009). As doctoral programs have a 50\% attrition rate (Cassuto, 2013), the classroom practices in these environments should be explored in greater depth. There is particularly a dearth of research on instructor practices in online doctoral environments, despite their growing enrollment. This study seeks to fill that gap in the literature. To that end, this study was driven by the following research question: What teaching practices are associated with building students' sense of community in online doctoral programs?

\section{Methods}

The researcher used qualitative methods to explore the topic of community building practices in an online program. Most research on online community is quantitative, and relies on survey data to explore students’ experiences (Black, Dawson \& Priem, 2008). By conducting a qualitative exploration of community, the researcher could provide thick description of participants' perspectives. By including participants' perspectives on the unique and evolving context of online environments, the researcher could enhance the novelty and validity of this study.

The researcher elected to use case study methods to conduct this qualitative study.

Case study allows researchers to use multiple data sources to create a thematic description of a bounded system (Merriam, 2014). The researcher made use of sources that are not typically used in online research, including video footage from online classrooms and interviews with online students. By drawing on multiple data points, the researcher could triangulate her findings and develop a unique and holistic portrayal of an online learning community. In the sections that 
follow the researcher describes the setting for the study and the data collection and analysis procedures.

\section{Setting for the Study}

The setting for the study was an online doctoral program at a major university on the West Coast that will be referred to by the pseudonym University of the West. Data were collected from students in the Doctorate of Education Program. Students in this program were midlevel professionals who worked in education, business, and government. Students took courses twice a week, and courses are approximately two hours long. Courses were delivered synchronously through a learning management system (LMS). The LMS used Adobe Connect software, and the video-conference technology allows students to see the web camera feeds of every student and the instructor. In the synchronous class meetings, students can also participate in a group chat, sent private messages, broke off into small groups, viewed a virtual blackboard and watched videos during whole group and small group instruction. According to Martin, Parker and Deale (2012), this type of online learning environment provides for dynamic interaction among participants, which promotes student engagement and facilitates peer-to-peer interaction. The courses also included an asynchronous component. Each course had a message board that is also housed in the LMS. On the message boards, instructors posted resources and updates, and students can ask questions and share information that is relevant to the course. In addition to a robust learning management system that allows students to see each other in synchronous courses and to communicate asynchronously via message boards, the program includes other components designed to increase student interaction. The program has a three-day required residential orientation that occurs during the first semester. Students travel from around the world to meet peers and instructors and learn to use the LMS. The program also utilizes a cohort model, meaning that the students are required to take classes with members of their cohort. This program was selected because it provides technical and social resources to maximize connection and thereby attends to some of the best practices associated with community building in the literature (Palloff \& Pratt, 2013).

\section{Data Collection}

Data for the project was collected from Spring 2015 to Spring 2016, in the first and second year of this three-year program. IRB approval was obtained prior to data collection. Data were drawn from three sources: 1) archived digital video recordings of the biweekly sessions of four courses, 2) threads from the message boards of the four online courses, and 3) interviews with 13 students. The researcher collected and analyzed video footage from biweekly meetings of four required courses. To obtain maximum variation in the sample, the researcher selected courses taught by different instructors. The researcher used a semi-structured protocol to gather the observational data (see Appendix A). The first half of the protocol was open-ended and allowed the researcher to document her observations. The second half of the protocol was aligned to the Community of Inquiry theoretical framework (Garrison et al., 2010) and allowed the researcher to provide examples of the instructor practices that may have supported students' sense of community based on the literature.

The researcher also analyzed the message board data from four classes. On the message boards, instructors posted updates for students, and students used the boards to ask questions and share resources. The researcher printed the transcripts of the message boards and analyzed them 
using a coding scheme drawn Garrison et al.’s (2010) Community of Inquiry theoretical framework (see Appendix C).

Finally, the researcher conducted interviews with students in the cohort to understand how students developed a sense of community. Interviews were 45 minutes and were semistructured. Questions were drawn from the theoretical framework (Garrison et al., 2001). Specifically, students were asked to define community, to explain their experience of community in the online classes, and to identify instructor practices that supported community. Students were also asked to identify any barriers to constructing community in the online classes, to note any instructor practices that they did not find helpful in building community, and to give their opinion on how to best support students in online environments. For a full outline of the interview protocol, see Appendix B.

Interview participants were selected by using theoretical sampling. Using Rovai's (2003) theory of persistence in distance education programs, the researcher sought out students who were active participants in classroom discussion as well as students who were less engaged. Active participants included those participants that talked frequently in the online classrooms, utilized the live chat regularly and responded to posts on the message boards. Less engaged students included students who did not participate in online class discussions, chats, or message board posts. The researcher sought students with varied levels of participation to gain maximum variation in the sample (Miles \& Huberman, 1994). There were 60 students in the first-year cohort, and the researcher interviewed thirteen of them.

\section{Data Analysis}

Data collection for this study produced message board transcripts, protocols from the observations of footage of taped classrooms, and interview transcripts. To analyze these documents, the researcher used traditional content analysis methods (DeWever, Schellens, Valcke, \& Van Keer, 2006). Content analysis relies on a system of categorizing, classifying and coding text to uncover themes and patterns (Hsieh \& Shannon 2005). The researcher used a theoretically aligned coding scheme to conduct the content analysis (Hsieh et al., 2005). The coding scheme was drawn from Garrison et al.'s (2010) Community of Inquiry theoretical framework, where researchers identify aspects of the instructors' course design, interpersonal communication and facilitation of discourse that may have contributed to community (see Appendix C). This coding scheme has been used in other studies on online students (Shea \& Bidjerano, 2009; Stodel, Thompson, \& MacDonald, 2006; Rourke \& Kanuka 2009).

The message board transcripts, observation protocols and interview transcripts were uploaded to NVivo software. The researcher conducted two cycles of coding. First the researcher coded everything that fit with the pre-determined codes from the coding scheme (Garrison et al., 2010; Saldaña, 2012). Next, uncoded data were analyzed to see if new codes emerged. For example, emergent codes included checking in and creating a personalized learning experience. The coding scheme was amended to reflect the emerging patterns, and codes that did not apply were removed from the data (see Appendix C). In the second cycle of coding the researcher reanalyzed the data using the established and emergent codes (Saldaña, 2012). To develop the case study, the researcher identified the key themes, patterns and processes that explained how students build community, triangulating these themes across data sources (Merriam, 2014). 
Themes that held across data sources, and particularly themes that were supported via member checks in interviews with students became the final case study. In the write up of the case, pseudonyms of the students and instructors were used to protect participants’ identity.

\section{Findings}

Students experience engagement, connection and community when instructors use a wide variety of technical and pedagogical practices (Garrison et al., 2010; Rovai, 2003). These practices include using the online medium effectively, setting a clear agenda for online instruction that is relevant to the curriculum and students' interests, responding to students needs with and facilitating discussions in which all students feel comfortable to share openly (Garrison, 2011). Observation of archived footage from the online classrooms, analysis of the course message boards, and analysis of interviews suggested that instructors used the aforementioned practices, and that these practices supported students' sense of community in three primary ways-by creating a warm and welcoming tone in the classroom, by using technology to create a personalized learning experience for students and by using technology to engage all students.

\section{Creating a Warm and Welcoming Tone}

Garrison et al. (2010) write that creating a warm and genuine atmosphere is one way that instructors can develop the teaching presence that is associated with community in an online classroom. Instructors in the University of the West demonstrated teaching presence by using a tone in the classrooms that students described as "warm" and "welcoming." Instructors gave the impression that they were interested in the academic, social and emotional lives of students, and that they were available to provide academic support. This tone was demonstrated in discussions in the online classrooms, and posts in the online message board. The instructors used the message board and the online classroom to invite students to share difficulties and remind students that they were available to provide academic assistance. The messages displayed a warm, welcoming tone, such as the following message by Dr. Johnstone:

A few of you have solicited input on plans or on write-up drafts...please don't hesitate to run questions by me. I would much rather give you some early direction to help you be confident you're heading the right way. Enjoy the rest of your week!

Another instructor, Dr. Marconni, created a warm tone by making herself available to student concerns and questions. Here is a post she placed in the online message board.

I will be diligent in being attentive to your academic needs, but if something slips past me or I don't respond to your email, please don't hesitate to resend your email or text me on my cell. Thanks everyone! Anne Marconni

The instructors demonstrated a welcoming tone by inviting students to ask questions, and a warm tone by providing praise and supportive feedback to students, such as in this message by Dr. Johnstone. 
Hey everyone, I genuinely enjoyed watching all of the pitches. I was impressed with the overall effort you put into them and the ways you incorporated the criteria we worked on - use of evidence, anecdotes, appealing to listeners' interests, etc. They were all different but collectively a really great job to all of you. I truly hope you found it helpful and can use some of the ideas going forward!

While each instructor put their own individual variations on creating a warm and welcoming tone, interview data suggested that the ways in which instructors engaged with students was effective in making them feel supported and connected. Speaking of his experience with instructors, Marcus said,

They helped me feel like I am a part of the program. They are compassionate, they are warm, they give me feedback that is constructive, it does not tear you down it builds you up.

During the interviews, Marcus and other students indicated that the warm and welcoming tone instructors used in the courses and in the message boards helped them feel supported and connected to the learning community. Observations of classrooms indicated that students felt positively about these overtures as well, as students would express gratitude and appreciation for their professor's willingness to engage and assist them.

Using technology to provide supportive feedback. Garrison et. al (2001) wrote that because of the physical and temporal separation inherent in an online program, distance learners may be more likely to feel a sense of separation from instructors and peers than students in faceto-face programs. In this program instructors helped students feel a sense of closeness and community in two ways—checking in and using technology to provide supportive feedback.

Checking in. Classes in the online program began informally, with students and instructors engaging in small talk about assignments, weather or random life events that occurred since previous week's class meeting. Instructors then facilitated a "check in" process, where he or she would spend a few minutes asking students about a random topic related to the informal chatter. Questions were usually about previous assignments or progress in the program. Sometimes questions would ask students about their professional experiences.

The questions asked during the check in served as an icebreaker and allowed students to express concerns or share successes at the start of the class. One student, Tom, spoke of his struggles in trying to get a promotion at work. The instructor and the students gave Tom feedback on how to showcase his skills to superiors and provided Tom with supportive feedback or practical resources on professional development. Another student, Jackie, spoke of an experience of successfully using class concepts to institute a reform at her job. Students and the instructor gave her affirmative feedback and encouraged her to keep up her efforts. In these and many more examples, the instructor-facilitated check in process allowed students to give and receive supportive feedback that was associated with a sense of community. Keshia described the impact of this informal process of connecting at the start of the class. 
Dr. Okamoto does this thing in saying, "how are you doing?". That answer can be "I'm exhausted”, “I’m overwhelmed”, “I just had a job interview, I don’t know if I'm going to get it or not"... we were comfortable enough (to share) and that built community. I think our professors were great at doing that. In my perspective professors were setting up that environment where we are scholars and peers but we are also support for one another as well.

For Keshia and for other students interviewed, checking in was a way that instructors provided emotional support to students. This type of support and engagement helped students feel like they were a part of a classroom community.

Creating a personalized learning experience. The instructors were skilled in using technology to create a personalized learning experience. This was demonstrated primarily in the ways that instructors provided feedback. Some instructors would provide video feedback to students on term papers. In these 5-minute videos students would receive feedback on their individual papers. Instructors gave ideas for improvement, provided praise for successful aspects of the students' work, and link the feedback to a discussion of the students' progress in the course in general. Interview data revealed that this technically enhanced mode of providing feedback provided academic and emotional benefits for students.

For Marcus, video feedback made the instructors recommendations easier to understand. I love the fact that Dr. Marconni gives video feedback which is easier to understand which gives me the opportunity to play it back if I didn't understand the first time and can make changes the first time.

For Keshia, receiving taped feedback tailored to her work created a level of personalization that contributed to her sense of community.

Dr. Marconni does this and it makes all the difference... when she gives us feedback on our larger papers she gave us feedback via video and I think that for me built community from a professor to student way in a way that minimized distance. As a long distance learner, it's one thing to get marks on a paper or track changes... 'I read your paper and I'm going to go over this this and this' and for me that made me feel very relational and that made me feel very connected to the campus community.

Students suggested that the nature of Dr. Marconni’s video feedback was supportive, and that providing it via video made it more accessible and easier to understand. Keshia said that video feedback "made me feel more connected than if Dr. Marconni would've just done track changes." Video feedback was described as a "thoughtful” touch that reflected the instructor's interest in the nuances of each individual's work. The personalized touch associated with the technologically enhanced feedback was linked to strengthening students' sense of community.

\section{Using Technology to Engage all Students}

Instructors use technology in a variety of different ways to support learning (Palloff \& Pratt, 2013). In this study instructors used technology to lecture or to create vibrant discussions, 
to facilitate dynamic and varied activities and to facilitate small group and whole group interactions that engage all students (Palloff \& Pratt, 2013; Rovai, 2003) Online classrooms have evolved greatly over the past decade (Palloff \& Pratt, 2013). The elements of a learning management system can make it easier to use a variety of pedagogical strategies (Dias \& Diniz, 2014). Researchers have found that the social network features of a learning management system can increase feelings of community (Yang, 2009). For example, tools that support collaborative learning, like wikis and blogs, can enhance students' feelings of connectedness online. Social network features like profiles, groups, and chat functions can promote more personalized interaction in the online space. At the University of the West, the learning management system featured many ways to help students connect. Students can see live video footage of all the students in the class, send instant messages to peers, break off into small groups and view a virtual blackboard. Observations revealed that instructors frequently used a range of these technological features to teach in the class. In interviews, students suggested that the instructors used the wide range of technical tools effectively, and this increased students' sense of community.

In an interview, June said that the instructors' use of video, dialogue and chat created an interactive and engaging classroom environment.

I think in my previous experiences with the online training programs it was like just watch a video and answer questions... so that's not what this online program is like. It's much more interactive and in many ways compared to my previous Master's program it feels like people participate more in the discussions.

The instructors used the multiple features of the LMS to help all students participate in class discussions. Stacey, a self-described "introvert," said that the instructor used the chat pod to help bring her and other less outspoken students into the conversation.

In the online class I can raise my hands and speak through the LMS or I can type something in the chat pod. What I've found is I might comment on something someone else is saying in the chat and that will lead to the instructor saying, 'you said this in the chat can you elaborate on that?'. It allows for other ways for me to enter the conversation instead of raising my hand and talking which I was not very comfortable with in a large class setting.

As Stacey's quote illustrates, instructors used technology to integrate all students into the course dialogue. By providing multiple avenues for communication in the classroom, instructors helped students like Stacey feel engaged and supported in the online classroom. The instructors in the online doctoral program used technology to facilitate bonds between peers as well. The LMS allowed the professor to place students into small groups of 3 to 4 . Students suggested that the most effective instructors utilized the small group feature frequently and effectively. One student, Tania, described her experience this way.

The standard classroom when I was in grad school was of a lecture variety. It was sort of one directional. There wasn't a lot of interaction with anyone other than the instructor. You might interact a little in labs but mostly my interaction was with my computer. In 
this program I'm doing all the work before hand and the instructor is really a facilitator in making sure that they facilitate the right kinds of discussions.

For many students, the "right kinds of discussions" were the ones that occurred in these small groups. Tania explained,

In the breakout rooms they can move us around and make sure that we are interacting with different groups of people so that's nice. There's also something to be said for interacting with the other nine classmates. In the breakout rooms you have good discussions and not then you share... and that's where the relationships are built.

Instructors skillfully utilized the learning management system to break students into groups of different sizes. As Tania's quote highlights, instructors used technology such as breakout rooms to ensure that students were connecting and collaborating in different ways. This strategy helped connect students to peers and allowed them to participate in small group discussions that engaged all students. In the small groups, students learned about the content and about each other, and to strengthen emerging bonds.

The instructors in the program at University of the West used a variety of strategies to support students' sense of community. They did not rely on one structure for class. At times, they inquired about students' concerns, while other times they focused on discussions of course content. They did not rely on one technical facet of the online experience either. They alternated easily between whole group discussions and small group breakout sessions. Instructors also integrated the live chat into all the course discussions, ensuring that all students could participate. By effectively using technology and teaching the curriculum while still attending to students' social and emotional needs, the instructors in this online program helped support online students' sense of community.

\section{Discussion}

Garrison et al.'s (2010) Community of Inquiry Framework suggests that a learning community is fostered when social presence, teaching presence and cognitive presence are high. When instructors make authentic connections with students and engage learners in a variety of ways, community is strengthened (Garrison et al., 2010). This paper explores the specific strategies that are associated students' sense of community in two of the required courses in one online doctoral program. These findings suggest that instructors in the classes in the online doctoral program under study developed high levels of teaching presence and social presence, and used multiple strategies to help increase first year students' sense of community. By checking in at the beginning of class, the instructors created an environment where doctoral students shared academic and work-related challenges and receive advice, support and resources from peers. By providing supportive feedback, the instructors built rapport with students that allowed them to feel comfortable with asking questions and accepting critiques. By using technology in a variety of ways, the instructors ensured that all students, particularly less vocal ones, participated equitably in the classroom discussions. 
The strategies used by instructors created a classroom where students felt engaged in the lives of their peers and felt comfortable giving and receiving feedback. The strategies helped create class discussion that were vibrant, engaging, nurturing and contributed to the students' sense of community in the online doctoral program.

The findings have several important implications for online learning at the graduate level. First, graduate students' benefit from a personalized online experience. Though graduate students often seek out education for professional advancement, their concerns go beyond their careers (Bess, 1978; Daniel, 2007). Like their undergraduate counterparts, graduate students desire to develop connections with peers (Bess, 1978; Rovai, 2003; Daniel, 2007). Instructors in the online doctoral program helped students develop connections with peers by facilitating conversations where all students could share openly and honestly about personal, professional and academic struggles. While instructors often focus on content and professionalization for graduate students, creating a space for open dialogue is essential for helping online graduate students create community (Gardner, 2008).

Secondly, the skilled use of technology can create personalization in an online class (Gruzd \& Haythornwaite, 2013). In the online doctoral program, instructors used things like recorded messages and small group activities to create feelings of closeness in an online space. To use technology in creative ways, instructors need adequate training and professional development (King, 2002). Many faculty lack training sufficient training for teaching in online environments (Burns, 2013). Therefore, faculty often struggle using online platforms and adapting curriculum and instruction to be dynamic and engaging in virtual environments (Burns, 2013; Gregory \& Salmon, 2013). Since the greatest increase in higher education is in online programs (Allen \& Seaman, 2013) universities would do well to ensure that faculty receive adequate professional development for online teaching.

Finally, the findings of this study suggest that instructors' ability to use technology to build community depends greatly on the type of technology available in the online space. Not all teaching platforms and learning management systems are created equally. Research suggests that robust, well-developed platforms can lead to greater interaction and connectivity among users (DeLone \& McLean, 2003). Faculty and staff must make critical choices about the types of learning management systems they purchase, and should bear in mind the ways in which different technologies can enhance or limit online students' connections.

\section{Limitations}

This exploratory case study examines instructor practices that support community in an online doctoral program. The study relies heavily on student perspectives, and a limitation is that it does not include instructors' perspectives on how they facilitated community. Online instructors face unique challenges, and a shortcoming of this study is that it did not include perspectives of faculty on teaching in this unique context. Another limitation of this work is that it did not explore instructor practices that undermined community. Students in the study were willing to share positive aspects of the community, but did not disclose much on negative experiences. Given the literature on online satisfaction and attrition, researchers can assume that there are teaching practices that are less favorable amongst online students. While this study 
uncovered practices that online students found beneficial, it does not highlight any factors that may have undermined online students' experiences and there was no attempt made to link these strategies to increased achievement or persistence.

\section{Conclusion}

Previous research had already suggested that that instructors play a significant role in helping online students develop a sense of community. In this study, doctoral students named strategies instructors had taken up as part of their role that made them feel like they were in a community. Instructors whose practices were highlighted in this study used a variety of pedagogical strategies, including creating a warm and welcoming tone, using technology to create a personalized learning experience and using technology to engage all learners. By facilitating discussions that were relevant to students' academic and personal goals, providing personalized feedback and skillfully using the learning management system to create collaborative groups, instructors helped students in the online doctoral program develop a sense of community. Findings suggest that effective online instructors use technology to facilitate dialogue, promote interactivity and attend to the social and emotional needs of students.

Sharla Berry is the Assistant Professor of Educational Innovation in the Gladys L. Benerd School of Education at the University of the Pacific.

\section{References}

Allen, I. E., \& Seaman, J. (2013). Changing course: Ten years of tracking online education in the United States. Sloan Consortium. Retrieved from http://www.onlinelearningsurvey.com/highered.html

Alvarez, I., Espasa, A., \& Guasch, T. (2012). The value of feedback in improving collaborative writing assignments in an online learning environment. Studies in Higher Education, 37(4), 387- 400. http://dx.doi.org/10.1080/03075079.2010.510182

Angelino, L. M., Williams, F. K., \& Natvig, D. (2007). Strategies to engage online students and reduce attrition rates. Journal of Educators Online. 4(2), n2. Retrieved from http://files.eric.ed.gov/fulltext/EJ907749.pdf

Barak, M., \& Rafaeli, S. (2004). On-line question-posing and peer-assessment as means for web-based knowledge sharing in learning. International Journal of HumanComputer Studies, 61(1), 84-103. http://dx.doi.org/10.1016/j.ijhcs.2003.12.005

Bess, J. L. (1978). Anticipatory socialization of graduate students. Research in Higher Education, 8(4), 289-317.

Black, E. W., Dawson, K., \& Priem, J. (2008). Data for free: Using LMS activity logs to measure community in online courses. The Internet and Higher Education, 11 (2), 65-70. http://dx.doi.org/10.1016/j.iheduc.2008.03.002 
Bolliger, D. U., \& Halupa, C. (2012). Student perceptions of satisfaction and anxiety in an online doctoral program. Distance Education, 33(1), 81-98. http://dx.doi.org/10.1080/01587919.2012.667961

Burns, M. (2013). Success, failure or no significant difference: Charting a course for successful educational technology integration. International Journal of Emerging Technologies in Learning, 8(1), 38-45. http://dx.doi.org/10.3991/ijet.v8il.2376

Cassuto, L. (2013, June 01). Ph.D. Attrition: How Much Is Too Much? Retrieved February 01, 2016, from http://chronicle.com/article/PhD-Attrition-How-Much-Is/140045/

Crawford-Ferre, H. G., \& Wiest, L. R. (2012). Effective online instruction in higher education. The Quarterly Review of Distance Education, 13(1), 11-14.

Daniel, C. (2007). Outsiders-within: Critical race theory, graduate education and barriers to professionalization. The Journal of Sociology and Social Welfare, 34, 25. Retrieved from: http://scholarworks.wmich.edu/jssw

Delone, W. H., \& McLean, E. R. (2003). The DeLone and McLean model of information systems success: a ten-year update. Journal of Management Information Systems, 19(4), 9-30.

DeWever, B., Schellens, T., Valcke, M., \& Van Keer, H. (2006). Content analysis schemes to analyze transcripts of online asynchronous discussion groups: A review. Computers \& Education, 46 (1), 6-28. http://dx.doi.org/10.1016/j.compedu.2005.04.005

Dewey, J. (1938). Experience and education. New York, NY: Collier.

Dias, S. B., \& Diniz, J. A. (2014). Towards an Enhanced Learning Management System for Blended Learning in Higher Education Incorporating Distinct Learners' Profiles. Educational Technology \& Society, 17(1), 307-319.

Gardner, S. K. (2008). Fitting the mold of graduate school: A qualitative study of socialization in doctoral education. Innovative Higher Education, 33(2), 125-138. http://dx.doi.org/10.1007/s10755-008-9068-x

Garrison, D. R. (2011). E-learning in the 21st century: A framework for research and practice. New York, NY: Routledge.

Garrison, D. R., Anderson, T., \& Archer, W. (2001). Critical thinking, cognitive presence, and computer conferencing in distance education. American Journal of Distance Education, 15(1), 7-23. http://dx.doi.org/10.1080/08923640109527071 
Garrison, D. R., Anderson, T., \& Archer, W. (2010). The first decade of the community of inquiry framework: A retrospective. The Internet and Higher Education, 13(1), 5-9. http://dx.doi.org/10.1016/j.iheduc.2009.10.003

Gray, B. (2004). Informal learning in an online community of practice. Journal of Distance Education, 19(1), 20-35.

Gregory, J., \& Salmon, G. (2013). Professional development for online university Teaching. Distance Education, 34(3), 256-270. http://dx.doi.org/10.1080/01587919.2013.835771

Gruzd, A., \& Haythornthwaite, C. (2013). Enabling community through social media. Journal of Medical Internet Research, 15(10). http://dx.doi.org/10.2196/jmir.2796

Hsieh, H. F., \& Shannon, S. E. (2005). Three approaches to qualitative content analysis. Qualitative Health Research, 15(9), 1277-1288. http://dx.doi.org/10.1177/1049732305276687

Ke, F., \& Hoadley, C. (2009). Evaluating online learning communities. Educational Technology Research and Development, 57(4), 487-510. http://dx.doi.org/10.1007/s11423-009-9120-2

King, K. P. (2002). Identifying success in online teacher education and professional development. The Internet and Higher Education, 5(3), 231-246. http://dx.doi.org/10.1016/S1096-7516(02)00104-5

Lovitts, B. E. (2001). Leaving the Ivory Tower: The causes and consequences of departure from doctoral study. Lanham, MD: Rowman \& Littlefield.

Martin, F., Parker, M. A., \& Deale, D. F. (2012). Examining interactivity in synchronous virtual classrooms. The International Review of Research in Open and Distributed Learning, 13(3), 228-261.

Merriam, S. B. (2014). Qualitative research: A guide to design and implementation. San Francisco, CA: John Wiley \& Sons.

Miles, M., \& Huberman, A. M. (1994). Qualitative analysis. Thousand Oaks, CA: SAGE.

Palloff, R. M., \& Pratt, K. (2013). Lessons from the virtual classroom: The realities of online teaching. San Francisco, CA: John Wiley \& Sons. 
Patterson, B., \& McFadden, C. (2009). Attrition in online and campus degree programs. Online Journal of Distance Learning Administration, 12(2). http://www.westga.edu/ distance/ojdla/summer122/patterson112.html

Rourke, L., \& Kanuka, H. (2009). Learning in communities of inquiry: A review of the Literature. International Journal of E-Learning \& Distance Education, 23(1),

Rovai, A. P. (2002). Building sense of community at a distance. The International Review of Research in Open and Distributed Learning, 3(1). http://www.irrodl.org/index.php/irrodl/article/view/79/152

Rovai, A. P. (2003). In search of higher persistence rates in distance education online programs. The Internet and Higher Education, 6(1), 1-16. http://dx.doi.org/10.1016/S1096-7516(02)00158-6

Rovai, A. P. (2007). Facilitating online discussions effectively. The Internet and Higher Education, 10(1), 77-88. http://dx.doi.org/10.1016/j.iheduc.2006.10.001

Saldaña, J. (2012). The coding manual for qualitative researchers Thousand Oaks, CA: Sage.

Shea, P., \& Bidjerano, T. (2009). Community of inquiry as a theoretical framework to foster "epistemic engagement" and "cognitive presence" in online education. Computers \& Education, 52(3), 543-553. http://dx.doi.org/10.1016/j.compedu.2008.10.007

Stodel, E. J., Thompson, T. L., \& MacDonald, C. J. (2006). Learners’ perspectives on what is missing from online learning: Interpretations through the community of inquiry framework. The International Review of Research in Open and Distributed Learning, 7(3). http://www.irrodl.org/index.php/irrodl/article/view/325/743

Stubb, J., Pyhältö, K., \& Lonka, K. (2011). Balancing between inspiration and exhaustion: PhD students' experienced socio-psychological well-being. Studies in Continuing Education, 33(1), 33-50. http://dx.doi.org/10.1080/0158037X.2010.515572

Waycott, J., Sheard, J., Thompson, C., \& Clerehan, R. (2013). Making students’ work visible on the social web: A blessing or a curse? Computers \& Education, 68, 86-95. http://dx.doi.org/10.1016/j.compedu.2013.04.026

Wolsey, T. D. (2008). Efficacy of instructor feedback on written work in an online program. International Journal on ELearning, 7(2), 311.

Wu, D., \& Hiltz, S. R. (2004). Predicting learning from asynchronous online discussions. Journal of Asynchronous Learning Networks, 8(2), 139-152. 
Building Community in Online Doctoral Classrooms: Instructor Practices that Support Community

Yang, S. H. (2009). Using blogs to enhance critical reflection and community of practice. Educational Technology \& Society, 12(2), 11-21.

Yuan, J., \& Kim, C. (2014). Guidelines for facilitating the development of learning communities in online courses. Journal of Computer Assisted Learning,30(3), 220-232. http://dx.doi.org/10.1111/jcal.12042 
Appendix A

Observation Protocol

Observation Protocol for Study of Community Building in Online Settings

\begin{tabular}{|l|l|}
\hline Date & Time \\
\hline Course & Lesson/Activity \\
& \\
\hline
\end{tabular}

General Observations

Observations will take place at 10-minute intervals

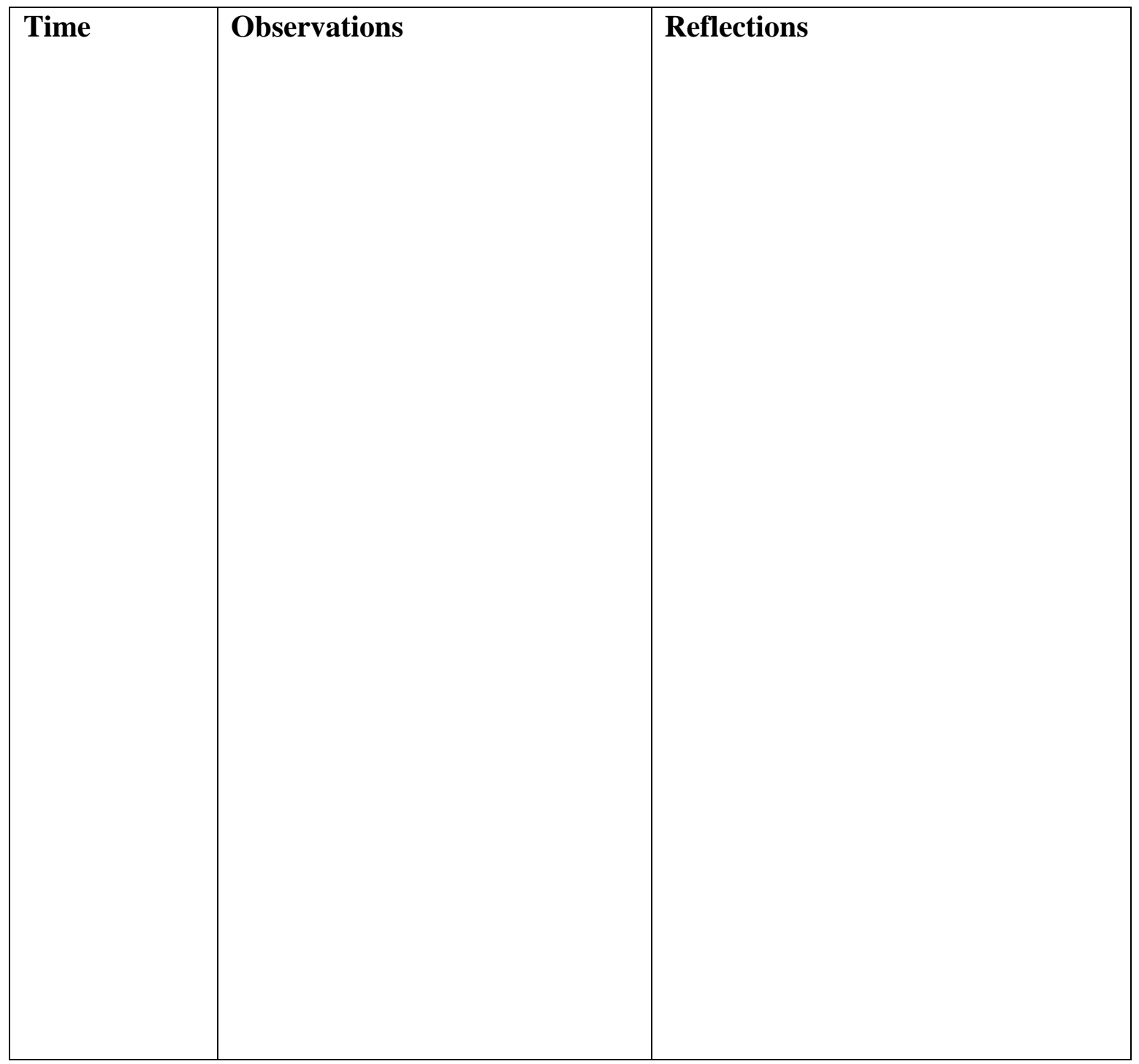




\title{
POST OBSERVATION REFLECTIONS
}

\section{Community of Inquiry}

\section{Teaching Presence}

"Teaching presence is defined as the design, facilitation, and direction of cognitive and social processes for the purpose of realizing personally meaningful and educational worthwhile learning outcomes." (Garrison, Anderson and Archer, p. 54)

\author{
Instructional Design and Organization \\ Note any examples of the following: \\ Utilizing medium effectively \\ Establishing netiquette \\ Making macro level contents about course content
}

\section{Facilitating Discourse}

Note any examples of the following:

Identifying areas of agreement/disagreement

Seeking to reach consensus/ understanding

Encouraging, acknowledging or reinforcing student contributions

Setting climate for learning

\section{Direct Instruction}

Note any examples of the following:

Present content/questions

Confirming understanding through assessment and explanatory feedback

Inject knowledge from diverse sources, e.g., textbook, articles, Internet, personal experiences (includes pointers to resources)

Respond to technical concerns 


\section{Social Presence}

"Social presence is the ability of learners to project their personal characteristics into the community of inquiry, thereby presenting themselves as 'real people." (Garrison, Anderson and Archer, pg. 30)

\begin{tabular}{|l|}
\hline $\begin{array}{l}\text { Interpersonal communication } \\
\text { Note any examples of the following: } \\
\text { Self-disclosure } \\
\text { Use of Humor }\end{array}$ \\
\hline $\begin{array}{l}\text { Open Communication } \\
\text { Continuing a thread } \\
\text { Quoting from others messages } \\
\text { Referring explicitly to others' messages } \\
\text { Asking questions } \\
\text { Complementing, expressing appreciation } \\
\text { Expressing agreement }\end{array}$ \\
\hline $\begin{array}{l}\text { Cohesive Communication } \\
\text { Addresses the group as we, us, our, group } \\
\text { Addressing or referring to participants by name } \\
\text { Communication that serves a purely social function, greetings, closures }\end{array}$ \\
\hline
\end{tabular}




\section{Cognitive Presence}

"Cognitive presence is the extent to which the participants in any particular configuration of a community of inquiry are able to construct meaning through sustained communication." (Garrison, Anderson and Archer, pg. 42)

In what ways do students make meaning in the classroom?

\section{Appendix B}

Interview Protocol

1. Can you please tell me a little bit about yourself? Where do you live, what do you do, and why you decided to do this particular program?

2. What's it like being in an online program? How does it compare to a face-to-face program? Describe your experience so far.

3. This is a study about community. How would you define community or learning community? Do you feel like you are in a community? Why?

4. Talk to me about your class experience. When you are in class does it feel like you are in a learning community?

5. What do instructors do to help you feel like you are in a learning community? Do the instructors do anything to undermine your sense of learning community?

6. Describe your experiences using the learning management system. How does the LMS help you connect? Are there any aspects of the LMS that are difficult to use? How do instructors help you use technology?

7. The program began with a residential orientation. What was that like? How did meeting peers in person at the beginning of the program impact your interactions throughout the school year?

8. Do you have any interactions with peers outside of class? Describe them.

9. Can you describe a time when you received support from members in your program? What happened, what was that like? 
Building Community in Online Doctoral Classrooms: Instructor Practices that Support Community

10. Are there any barriers toward forming community in this online program? Explain.

11. If you were designing a program, how would you design it to improve how students interact and connect?

12. Would you like to add anything about how online students construct community?

Thank you for your participation. 


\section{Appendix C Coding Scheme}

This coding scheme is taken from Garrison, D. R., Anderson, T., \& Archer, W. (2010). The first decade of the community of inquiry framework: A retrospective. The Internet and Higher Education, 13(1), 5-9.

Social Presence -the ability of learners to project their personal characteristics into the community of inquiry, thereby presenting themselves as "real people.” Examples of social presence include self-disclosure, humor, open communication, continuing threads, and addressing the group using inclusive pronouns.

Teaching Presence - the design, facilitation, and direction of cognitive and social processes for the purpose of realizing personally meaningful and educational worthwhile learning outcomes. Examples of teaching presence include using the online medium effectively, including all students in discussions and encouraging student contributions.

Cognitive Presence - the extent to which the participants in any particular configuration of a community of inquiry are able to construct meaning through sustained communication. Examples of cognitive presence include making connections to course content and real world experiences.

The following codes emerged from the data.

Social/ Emotional Support - The process of asking questions and providing answers that were relevant to students' social and emotional needs.

Creating A Personalized Learning Experience - The process of asking questions or providing feedback that was tailored to the needs of an individual student.

Checking In - The process of asking students to share their feelings with the class 